\title{
Suplemento múltiplo com ionóforos para novilhos em pasto: consumo, fermentação ruminal e degradabilidade in situ
}

[Multiple supplement with ionophores for grazing steers: intake, ruminal fermentation, and in situ degradability]

\author{
M.H.F. Mourthe ${ }^{1}$, R.B. Reis $^{2}$, M.M. Ladeira ${ }^{3}$, R.C. Souza ${ }^{1}$, S.G. Coelho², H.M. Saturnino ${ }^{2}$ \\ ${ }^{1}$ Aluno de pós-graduação - EV-UFMG - Belo Horizonte, MG \\ ${ }^{2}$ Escola de Veterinária - UFMG \\ Caixa Postal 567 \\ 30123-970 - Belo Horizonte, MG \\ ${ }^{3}$ Universidade Federal de Lavras - Lavras, MG
}

\begin{abstract}
RESUMO
Avaliou-se o efeito do suplemento múltiplo com ionóforos sobre o consumo, a fermentação ruminal e a degradabilidade in situ da matéria seca da forragem. Utilizaram-se cinco novilhos Holandês $\mathrm{x}$ Zebu fistulados no rúmen, com peso vivo médio de $350 \mathrm{~kg}$, em delineamento em quadrado latino. Os tratamentos foram: suplementação múltipla sem ionóforos (CONT); suplementação múltipla com 100mg/cab/dia de monensina (M100); suplementação múltipla com 200mg/cab/dia de monensina (M200); suplementação múltipla com 100mg/cab/dia de lasalocida (L100); e suplementação múltipla com 200mg/cab/dia de lasalocida (L200). O uso de ionóforos no suplemento não influenciou o consumo de forragem, que foi, em média, 7,24kg MS/dia. A presença de ionóforos resultou em ligeiro aumento do $\mathrm{pH}$ ruminal em relação à ausência desses aditivos $(\mathrm{P}<0,05)$. Houve diferença na concentração do $\mathrm{N}-\mathrm{NH}_{3}$ apenas para os teores de ionóforos em que $200 \mathrm{mg} / \mathrm{cab} / \mathrm{dia}$ reduziu a quantidade de $\mathrm{N}^{-\mathrm{NH}_{3}}$. As concentrações de acetato, propionato e butirato não foram influenciadas pela inclusão, pelo tipo ou pelos teores de ionóforos. A fração solúvel média (A) da Brachiaria decumbens foi igual a 22\%, e a fração insolúvel potencialmente degradável média (B) igual a $65 \%$, resultando em degradação potencial média de $87 \%$. A taxa de degradação média (c) foi de 0,03/hora. Os ionóforos não alteraram a degradação in situ da matéria seca.
\end{abstract}

Palavras-chave: ruminante, lasalocida, monensina, suplementação

\begin{abstract}
The effect of multiple supplement with ionophores was evaluated on intake, ruminal fermentation, and in situ degradability of dry matter (DM) of the pasture forage. Five rumen fistulated Holstein x Zebu steers averaging $350 \mathrm{~kg}$ of $B W$ were used. The animals were grouped in five different paddocks under Latin Square experimental design. The treatments were multiple supplement without ionophores (CONT); multiple supplement with $100 \mathrm{mg}$ of monensin/animal/day (M100); multiple supplement with 200mg of monensin/animal/day (M200); multiple supplement with 100mg of lasalocid/animal/day (L100); multiple supplement with $200 \mathrm{mg}$ of lasalocid/animal/day (L200). The pasture intake was $7.24 \mathrm{~kg} D M /$ day and it was not affected by ionophores. The average $\mathrm{pH}$ was influenced $(\mathrm{P}<0.05)$ by the presence of the ionophores in the supplements. There rumen $\mathrm{N}-\mathrm{NH}_{3}$ concentration was negatively influenced by the ionophores levels in the multiple supplement. The molar concentrations of acetate, propionate, and butirate in the rumen were not affect by the presence, type, or level of ionophores. The mean soluble fraction $A$ of Brachiaria decumbens was $22 \%$, the mean potential degradable insoluble fraction (B) was $65 \%$, and the degradability was $87 \%$. The mean degradation rate (c) was $0.03 / h$. The ionophores did not affect $D M$ in situ degradability.
\end{abstract}

Keywords: ruminant, lasalocid, monensin, suplementation

Recebido em 25 de outubro de 2009

Aceito em 22 de dezembro de 2010

E-mail: kikolider@yahoo.com.br 


\section{INTRODUÇÃo}

Os machos leiteiros representam oportunidade de renda extra no sistema de produção de leite em pasto, principalmente os oriundos dos cruzamentos com raças zebuínas. Para isso, há necessidade de alternativas que contribuam para evitar a descontinuidade da curva de crescimento dos animais durante o período de seca. Nesse período, as gramíneas de clima tropical apresentam baixa taxa de crescimento e problemas de qualidade nutricional, pois teores de proteína bruta (PB) abaixo de 6,5\% limitam o desenvolvimento dos microrganismos do rúmen, a digestibilidade e o consumo da forragem, o que resulta em baixo desempenho dos animais (Minson, 1990).

O consumo é fator importante no desempenho animal. Estratégias que aumentem o consumo de matéria seca do pasto, de modo a propiciar maior ingestão de nutrientes, poderão refletir no maior ganho de peso dos animais. Dentre as alternativas, há a vedação de pastagens, a suplementação múltipla e o uso de ionóforos. Estas ajudam a manter a curva de crescimento dos animais durante o período da seca, resultando em ciclo de produção mais curto (Ruas et al., 2000).

A vedação do pasto constitui a retirada dos animais deste no período chuvoso para utilização no período de seca. As sobras do pasto na época das chuvas são constituídas de resíduos maduros de baixo valor nutritivo. Entretanto, a suplementação constitui opção de fornecer os nutrientes deficientes da forragem remanescente, com base nas necessidades e nos objetivos específicos do programa de manejo do rebanho. $\mathrm{O}$ termo suplemento refere-se a fontes de alimentos ricos em nutrientes específicos, como proteína, energia, fósforo, sódio, entre outros, corrigindo as deficiências na dieta do animal em pastejo (Paulino et al., 2002).

Os ionóforos também podem ser incluídos nos suplementos múltiplos e têm o propósito de melhorar a eficiência alimentar. Os ionóforos são antibióticos que provocam aumento da eficiência energética, mediante maior produção de propionato e menor produção de metano; aumento da eficiência proteica, ao diminuírem a proteólise ruminal, além de contribuírem para a diminuição da produção de ácido lático (Bergen e Bates, 1984). No Brasil, os mais utilizados são a monensina sódica e a lasalocida sódica. No entanto, não foi verificado nenhum trabalho nacional que comparou os efeitos destes ionóforos sobre o metabolismo ruminal de novilhos em pastejo durante o período seco do ano.

O objetivo do presente estudo foi avaliar o uso de ionóforos na suplementação múltipla, em diferentes níveis de inclusão sobre o consumo, a fermentação ruminal e a degradabilidade in situ da matéria seca da forragem, em novilhos leiteiros, durante o período da seca.

\section{MATERIAL E MÉTODOS}

O estudo foi realizado no período de 20 de junho a 5 de outubro de 2005. Utilizaram-se cinco novilhos mestiços, Holandês x Zebu, castrados, com peso vivo inicial médio de $350 \pm 45 \mathrm{~kg}$, distribuídos em cinco piquetes de pastagem de Brachiaria decumbens.

Os tratamentos utilizados foram: controle suplementação múltipla sem ionóforos (CONT); suplementação múltipla com 100mg/cab/dia de monensina (M100); suplementação múltipla com 200mg/cab/dia de monensina (M200); suplementação múltipla com 100mg/cab/dia de lasalocida (L100); suplementação múltipla com 200mg/cab/dia de lasalocida (L200). Os produtos utilizados foram o Rumensin com $10 \%$ de monensina sódica (Elanco $\left.{ }^{\circledR}\right)$ e o Taurotec com $15 \%$ de lasalocida sódica (Alpharma ${ }^{\circledR}$ ). A quantidade de ionóforo adicionada aos suplementos visou ao consumo aproximado de 15 ou 30mg de ionóforo por $\mathrm{kg} / \mathrm{MS}$, considerando-se o consumo do suplemento em 0,1\% do peso vivo (PV) do animal.

Os suplementos foram fornecidos diariamente às sete horas da manhã. Os ionóforos foram misturados aos suplementos no momento do fornecimento destes, que foram balanceados de acordo com os disponíveis no mercado (Tab. 1). 
Suplemento múltiplo com ionóforos...

Tabela 1. Porcentagem de ingredientes do suplemento múltiplo e composição química

\begin{tabular}{lclc}
\hline Ingrediente & Porcentagem & Nutriente & Porcentagem \\
\hline Milho & 34,0 & Matéria seca & 87,8 \\
Farelo de soja & 5,0 & Proteína bruta & 36,1 \\
Farelo de algodão & 12,0 & Carboidratos totais & 16,6 \\
Ureia & 10,5 & Matéria mineral & 45,9 \\
Fosfato bicálcico & 10,7 & Extrato etéreo & 1,4 \\
Calcário calcítico & 4,5 & Carboidratos não fibrosos & 6,4 \\
Sal comum & 20,0 & FDN & 12,5 \\
Microminerais & 3,3 & FDA & 7,3 \\
& & NIDIN & 2,3 \\
& & NIDA & 1,9 \\
\hline
\end{tabular}

FDN: fibra insolúvel em detergente neutro; FDA: fibra insolúvel em detergente ácido; NIDIN: nitrogênio insolúvel em detergente neutro; NIDA: nitrogênio insolúvel em detergente ácido.

O delineamento experimental foi o quadrado latino $5 \times 5$, com períodos experimentais de 21 dias, sendo os primeiros 14 dias para adaptação dos animais ao suplemento. Do $15^{-}$ao $19^{\circ}$ dia de cada período, foram realizadas três coletas de fezes diariamente, via ampola retal, para posterior análise do cromo para fornecer a estimativa da produção fecal. A fibra insolúvel em detergente ácido indigestível (FDAi) foi utilizada como marcador interno para cálculo do consumo da matéria seca da forragem. Para isso, foram utilizadas amostras de pasto ingerido e de fezes de cada animal, colocadas em sacos de náilon e incubadas no rúmen por 144 horas. As amostras do pasto ingerido foram obtidas após o rúmen ter sido totalmente esvaziado e os animais terem sido colocados para pastejo durante 40 minutos.

O consumo de matéria seca da forragem foi calculado por meio do produto da produção fecal pela FDAi presente nas fezes dividido pela FDAi presente na forragem. O consumo do suplemento individual não foi mensurado, pois ocorreram dois experimentos simultâneos, em que os animais foram suplementados coletivamente. Entretanto, estimou-se o consumo individual médio diário por meio da diferença entre a quantidade fornecida e as sobras no cocho.

Do $16^{0}$ ao $20^{\circ}$ dia, foram incubados os sacos de náilon para determinação da taxa de degradabilidade in situ da matéria seca do pasto ingerido. Os sacos foram mergulhados em água por 10 minutos e, antes de serem incubados no rúmen, dois sacos foram retirados para determinar a fração solúvel no tempo 0 . As retiradas ocorreram às três, seis, 12, 24, 48, 72 e
96 horas após a incubação. Para determinação da degradabilidade potencial e efetiva, foram adotados os modelos de Orskov e McDonald (1979). Foram consideradas as taxas de passagem de 0,02 e 0,05/hora.

No último dia de cada período experimental, foram realizadas coletas de líquido ruminal (100mL) para determinação do pH, das concentrações de nitrogênio amoniacal $\left(\mathrm{N}-\mathrm{NH}_{3}\right)$ e dos ácidos graxos voláteis (AGVs): acetato, propionato e butirato. As coletas foram feitas às zero, duas, quatro, seis, oito e 10 horas após o fornecimento dos suplementos. As análises de $\mathrm{pH}$ foram feitas imediatamente após as coletas, utilizando-se pHmetro digital. Para análise do $\mathrm{N}-\mathrm{NH}_{3}$, utilizou-se a titulação com $\mathrm{HCl} 0,01 \mathrm{~N}$, após destilação com $\mathrm{MgO}_{2}$, usando-se ácido bórico como solução receptora (Official...,1990). Os AGVs foram determinados por cromatografia gasosa no aparelho Shimadzu ${ }^{\circledR}$, modelo gás cromatographo GC17A, utilizando-se coluna capilar com fase estacionária NUCOL.

As amostras do pasto ingerido foram processadas e analisadas para matéria seca (MS) e proteína bruta (PB) de acordo com Silva e Queiroz (2002), e a determinação da fibra insolúvel em detergente neutro (FDN) segundo Van Soest et al. (1991).

As análises estatísticas foram realizadas segundo o PROC GLM do pacote estatístico SAS/1997. Utilizou-se a análise de contrastes ortogonais para a presença, o tipo e a dose de ionóforos. Efeitos foram considerados significativos quando $\mathrm{P}<0,05$. 


\section{RESULTADOS E DISCUSSÃO}

O pasto ingerido apresentou valores nutricionais de $11,3 \%$ para MS; 5,9\% para PB; e 72,2\% para FDN. O baixo valor de MS é explicado pela sua forma de obtenção, que foi a retirada por meio de coleta ruminal.

O consumo de forragem variou de 6,40 a $8,25 \mathrm{~kg}$ MS/dia (Tab. 2). Em média, os animais consumiram 2,1\% do PV em MS, e o uso de ionóforos no suplemento não influenciou o consumo $\quad(\mathrm{P}>0,05)$. Outros experimentos realizados em condições similares também encontraram consumo de matéria seca semelhante. Ruas et al. (2000) verificaram, em vacas Nelore em pasto, consumo entre 8,9 e $10,4 \mathrm{~kg}$ MS/dia, representando entre 2,1 e 2,2\% do PV. Ribeiro et al. (2005), ao trabalharem com novilhas Holandês X Gir com peso vivo médio de $212 \mathrm{~kg}$, observaram consumo de 5,40kg MS de Brachiaria brizantha com $8 \%$ de PB e $70 \%$ de FDN.
Os experimentos que envolvem consumo de animais em pasto, em geral, atribuem grande parte da ingestão de matéria seca à qualidade da forrageira. Segundo Van Soest (1994), o consumo pode estar ligado ao teor de FDN em dietas, com maior proporção do volumoso. Sabe-se que os teores de FDN das forrageiras de clima tropical são geralmente altos, o que resultaria em maior tempo de retenção no rúmen e redução do consumo. O consumo médio de FDN obtido foi de 1,5\% do PV. Segundo Mertens (1992), com base em resultados de vários experimentos para se encontrar a concentração ótima de FDN para vacas em lactação, o consumo de FDN é de 1,2\% do PV. Todavia, Aroeira (1997), em revisão de vários trabalhos de consumo de forrageiras de clima tropical, encontrou valores de até $1,5 \%$ do $\mathrm{PV}$, em novilhos em pastagem do gênero Cynodon. O consumo médio do suplemento foi de $0,49 \mathrm{~kg}$, ou $0,17 \%$ do $\mathrm{PV}$, não apresentando grandes diferenças entre os tratamentos. Outros experimentos também não observaram efeito de ionóforos sobre o consumo (Martineou et al., 2007).

Tabela 2. Consumo de matéria seca (CMSF), de fibra insolúvel em detergente neutro (CFDN) e de proteína bruta da forragem (CPBF), por novilhos em pasto que receberam suplemento múltiplo com ou sem ionóforos

\begin{tabular}{|c|c|c|c|c|c|c|c|c|c|}
\hline & \multicolumn{5}{|c|}{ Tratamento } & \multirow[b]{2}{*}{ EPM } & \multicolumn{3}{|c|}{ Contraste (Valor de P) } \\
\hline & CONT & M100 & M200 & L100 & $\mathrm{L} 200$ & & C x I & $\mathrm{M} \times \mathrm{L}$ & $100 \times 200$ \\
\hline CMSF (kg) & 7,71 & 6,40 & 7,01 & 6,81 & 8,25 & 0,46 & 0,61 & 0,43 & 0,33 \\
\hline CPBF (g) & 453 & 376 & 412 & 400 & 484 & 0,03 & 0,64 & 0,35 & 0,32 \\
\hline CFDN (kg) & 5,60 & 4,65 & 5,09 & 4,95 & 5,99 & 0,39 & 0,44 & 0,40 & 0,23 \\
\hline CMSF (\%PV) & 2,20 & 1,83 & 2,00 & 1,95 & 2,36 & 0,13 & 0,61 & 0,43 & 0,33 \\
\hline CFDN (\%PV) & 1,60 & 1,33 & 1,46 & 1,41 & 1,71 & 0,11 & 0,44 & 0,40 & 0,23 \\
\hline
\end{tabular}

CONT: suplementação múltipla sem inclusão de ionóforos; M100: suplementação múltipla mais 100mg/cab/dia de monensina; M200: suplementação múltipla mais 200mg/cab/dia de monensina; L100: suplementação múltipla mais 100mg/cab/dia de lasalocida; L200: suplementação múltipla mais 200mg/cab/dia de lasalocida; EPM: erro-padrão da média; C x I: contraste entre controle e ionóforos; MxL: contraste entre monensina e lasalocida; 100 x 200: contraste entre 100mg x 200mg; significativo $=\mathrm{P} \leq 0,05$.

Os valores obtidos para o pH médio (Tab. 3) foram influenciados $(\mathrm{P}<0,05)$ pela presença dos ionóforos nos suplementos, o que pode ser explicado pelo menor valor de $\mathrm{pH}$ mínimo para o tratamento-controle em relação aos outros tratamentos. Apesar do efeito positivo dos ionóforos, os animais não apresentaram variações acentuadas do $\mathrm{pH}$ ruminal durante todo o dia, pois houve estímulo da salivação durante a ingestão e ruminação dos alimentos, provocado pela grande quantidade de fibra da dieta. A forragem ingerida continha $72 \%$ de FDN.
Não houve diferenças na concentração do $\mathrm{N}-\mathrm{NH}_{3}$ entre os contrastes controle vs. ionóforos e monensina vs. lasalocida $(\mathrm{P}>0,05)$. Entretanto, o consumo de ionóforos (100 vs. 200) reduziu a quantidade de $\mathrm{N}_{-} \mathrm{NH}_{3}$, ou seja, comprovou o efeito negativo dos ionóforos sobre as bactérias que produziram alta quantidade de $\mathrm{N}_{-} \mathrm{NH}_{3}$. Em revisão de vários trabalhos com ionóforos, McGuffey et al. (2001) citaram o efeito dos ionóforos na diminuição da proteólise ruminal e na deaminação dos aminoácidos, com diminuição, assim, do $\mathrm{N}-\mathrm{NH}_{3}$ e aumento do 
aporte de proteína e aminoácidos de fonte dietética para o intestino delgado.

$\mathrm{O}$ valor mínimo de $\mathrm{N}-\mathrm{NH}_{3}$ para não causar inibição da fermentação microbiana é de $5 \mathrm{mg} / \mathrm{dL}$ de líquido ruminal, de acordo com Satter e Slyter (1974), e de 10mg/dL, segundo Leng (1990).
Todos os tratamentos apresentaram concentrações baixas ou bem próximas dos mínimos propostos por esses autores. A concentração média do $\mathrm{N}-\mathrm{NH}_{3}$ foi de $5,9 \mathrm{mg} / \mathrm{dL}$, exceto para o tratamento L200, que apresentou valor de $\mathrm{N}-\mathrm{NH}_{3}$ abaixo de $5 \mathrm{mg} / \mathrm{dL}$.

Tabela 3. Valores de $\mathrm{pH}$, nitrogênio amoniacal $\left(\mathrm{N}-\mathrm{NH}_{3}\right)$ em mg/dL, ácidos graxos voláteis totais (AGVt), acetato, propionato, butirato, em $\mathrm{mMol} / 100 \mathrm{~mL}$ e relação acetato:propionato de novilhos a pasto recebendo suplemento múltiplo com ou sem ionóforos

\begin{tabular}{|c|c|c|c|c|c|c|c|c|c|}
\hline & \multicolumn{5}{|c|}{ Tratamento } & \multirow[b]{2}{*}{ EPM } & \multicolumn{3}{|c|}{ Contraste } \\
\hline & CONT & M100 & M200 & L100 & L200 & & $\mathrm{C} \times \mathrm{I}$ & $M \times L$ & $100 \times 200$ \\
\hline pH médio & 6,7 & 6,7 & 6,7 & 6,8 & 6,7 & 0,007 & $* * *$ & NS & NS \\
\hline pH mínimo & 6,3 & 6,6 & 6,6 & 6,2 & 6,4 & 0,014 & $* * *$ & NS & $* * *$ \\
\hline pH máximo & 7,1 & 7,0 & 7,0 & 7,0 & 7,1 & 0,016 & NS & NS & NS \\
\hline $\mathrm{N}-\mathrm{NH}_{3}$ médio & 7,1 & 7,1 & 5,7 & 5,4 & 4,3 & 0,286 & NS & NS & $* * *$ \\
\hline AGVt & 17,4 & 16,4 & 16,4 & 17,1 & 17,4 & 0,429 & NS & NS & NS \\
\hline Acetato & 14,0 & 13,5 & 13,2 & 13,8 & 14,0 & 0,376 & NS & NS & NS \\
\hline Propionato & 2,5 & 2,2 & 2,4 & 2,5 & 2,6 & 0,076 & NS & NS & NS \\
\hline Butírico & 0,8 & 0,7 & 0,8 & 0,8 & 0,8 & 0,019 & NS & NS & NS \\
\hline Ac:Prop & 5,5 & 6,1 & 5,6 & 5,6 & 5,4 & 0,013 & NS & NS & NS \\
\hline
\end{tabular}

CONT: suplementação múltipla sem inclusão de ionóforos; M100: suplementação múltipla mais 100mg/cab/dia de monensina; M200: suplementação múltipla mais 200mg/cab/dia de monensina; L100: suplementação múltipla mais 100mg/cab/dia de lasalocida; L200: suplementação múltipla mais 200mg/cab/dia de lasalocida; CxI: contraste entre controle e ionóforos; MxL: contraste entre monensina e lasalocida; 100 x 200: contraste entre 100mg x 200mg; ***significativo $(\mathrm{P}<0,05)$; NS: não significativo; EPM: erro-padrão da média.

Neste experimento, somente os valores do $\mathrm{N}$ $\mathrm{NH}_{3}$ não permitem afirmar se houve menor eficiência na utilização do nitrogênio, pois não foram quantificadas a síntese de proteína microbiana e mesmo a atividade específica de produção de amônia (AEPA). Oliveira et al. (2005) também não encontraram variação no N$\mathrm{NH}_{3}$, em novilhos alimentados com dieta à base de feno de Brachiaria decumbens e inclusão de $250 \mathrm{mg} / \mathrm{cab} /$ dia de monensina, com o valor médio de $7,93 \mathrm{mg} / \mathrm{dL}$. Semelhante resultado foi obtido por Jacques et al. (1987), ao fornecerem 60, 120 e $180 \mathrm{mg} / \mathrm{cab} /$ dia de lasalocida a novilhos em pastagem de inverno.

As concentrações de ácidos graxos voláteis totais (AGVs), acetato, propionato e butirato, e a relação acetato:propionato não foram diferentes entre os contrastes $(\mathrm{P}>0,05)$. Os valores de AGVs variaram de 16,4 a 17,4 e, segundo Bergman (1990), a faixa ótima é de 6 a $15 \mathrm{mMol} / 100 \mathrm{~mL}$. O efeito dos ionóforos em aumentar a proporção do propionato, em detrimento da proporção do acetato e butirato, não foi encontrado neste experimento.
Resultados semelhantes foram observados por Amaro et al. (2002) e Gehman et al. (2008). No entanto, todos os demais trabalhos consultados, nas mais variadas condições, com diferentes tipos de dietas, proporção de volumoso:concentrado, tipo e concentrações de ionóforos e categorias animal, citaram a diminuição da relação acetato:propionato.

O efeito dos ionóforos em selecionar bactérias celulolíticas Gram-negativas, como o Fibrobacter succinogenes, produtoras de succinato (precursor de propionato), pode ter acontecido em proporção insuficiente para causar alterações na proporção dos AGVs. Houve alta produção de acetato, o que pode resultar em maior perda energética pela produção de metano e dióxido de carbono.

Os parâmetros de degradabilidade in situ da MS, para cada tratamento, são apresentados na Tab. 4. A presença, o tipo e a quantidade do ionóforo não influenciaram a degradabilidade in situ da MS ( $P>0,05)$. A fração solúvel média (A) foi igual a 22,2\%, e a fração insolúvel 
potencialmente degradável média (B) igual a $65,7 \%$, resultando em uma degradação potencial média da Brachiaria decumbens de 87,9\%. A taxa de degradação média (c) obtida foi de 0,03/hora. A degradabilidade efetiva média foi de 59 e 45\%, considerando-se as taxas de passagem de 0,02 e 0,05/hora, respectivamente. Os ionóforos não alteraram a degradação da MS, e como o material incubado continha $72 \%$ de FDN, pode-se concluir que não houve efeito dos ionóforos na degradabilidade da fibra.
Resultados semelhantes aos deste experimento foram relatados anteriormente por outros autores. Rodrigues et al. (2000) não encontraram diferença significativa na degradabilidade potencial da FDN e FDA do capim coast cross (Cynodon dactylon (L.) Pers.) com a presença de 200mg/cab/dia de lasalocida. Knowlton et al. (1996) também não verificaram efeito da lasalocida (360mg/cab/dia) na dieta sobre a degradação da MS, FDN e amido.

Tabela 4. Parâmetros de degradação potencial (DP) e efetiva (DE) da forragem ingerida por novilhos em pasto que receberam suplemento múltiplo com ou sem ionóforos

\begin{tabular}{|c|c|c|c|c|c|c|c|c|c|}
\hline & \multicolumn{5}{|c|}{ Tratamento } & \multirow[b]{2}{*}{ EPM } & \multicolumn{3}{|c|}{ Contraste (Valor de P) } \\
\hline & Controle & M100 & M200 & L100 & L200 & & CxI & LxM & 100x200 \\
\hline \multicolumn{10}{|l|}{$\mathrm{DP}, \%$} \\
\hline A & 21,2 & 23,7 & 22,8 & 21,5 & 21,7 & 0,620 & 0,41 & 0,82 & 0,25 \\
\hline B & 63,6 & 69,5 & 64,4 & 65,4 & 65,6 & 1,457 & 0,48 & 0,68 & 0,48 \\
\hline C & 0,03 & 0,03 & 0,03 & 0,03 & 0,03 & 0,002 & 0,64 & 0,75 & 0,91 \\
\hline \multicolumn{10}{|l|}{ DE, \% } \\
\hline 0,02 & 58,2 & 61,7 & 58,4 & 58,4 & 59,1 & 0,756 & 0,54 & 0,46 & 0,46 \\
\hline 0,05 & 44,1 & 46,4 & 44,5 & 44,2 & 44,5 & 0,724 & 0,64 & 0,64 & 0,52 \\
\hline
\end{tabular}

CONT: suplementação múltipla sem inclusão de ionóforos; M100: suplementação múltipla mais 100mg/cab/dia de monensina; M200: suplementação múltipla mais 200mg/cab/dia de monensina; L100: suplementação múltipla mais 100mg/cab/dia de lasalocida; L200: suplementação múltipla mais 200mg/cab/dia de lasalocida; EPM: erro-padrão da média; C x I: contraste entre controle e ionóforos; M x L: contraste entre monensina e lasalocida; 100 x 200: contraste entre 100mg x 200mg; A: fração solúvel da forragem; B: fração insolúvel potencialmente degradável, c: taxa de degradação ruminal (\%/h); 0,02 e 0,05: taxas de passagem; significativo ( $\mathrm{P} \leq 0,05)$.

Segundo McGuffey et al. (2001), a degradação da fibra é inalterada pelos ionóforos, pois o aumento das fibrolíticas resistentes, como Fibrobacter succinogenes, pode compensar a redução de espécies, como os Ruminococcus sp. Portanto, o maior tempo de retenção da fibra no rúmen pode ter contribuído para manter a digestão normal da fibra. Os valores médios de $7,4 \%$ de $\mathrm{PB}$ na dieta consumida e $5,1 \mathrm{mg} / \mathrm{dL}$ de $\mathrm{N}-\mathrm{NH}_{3}$ ruminal estão bem próximos dos valores mínimos considerados na literatura para que não haja redução na produção microbiana ruminal e na degradação da fibra.

A forragem correspondeu a 95\% da MS na dieta consumida e apresentou teor de FDN de $72 \%$ da MS. Nestas condições, pode ser necessária maior quantidade de ionóforos na suplementação múltipla de novilhos em pasto, durante período da seca, para alterar significativamente os parâmetros da fermentação ruminal e a degradabilidade in situ da MS da forragem.

\section{REFERÊNCIAS BIBLIOGRÁFICAS}

AMARO, F.R.; LUCCI, C.S.; PEIXOTO JÚNIOR, K.C. et al. Efeitos dos níveis e períodos de adaptação à lasalocida sódica sobre os parâmetros da fermentação ruminal. Rev. Bras. Zootec., v.31, p.2299-2306, 2002.

AROEIRA, L.J.M. Estimativas de consumo de gramíneas tropicais. In: TEIXEIRA, J.C. (Ed). SIMPÓSIO INTERNACIONAL DE DIGESTIBILIDADE EM RUMINANTES. 1997, Lavras. Anais... Lavras: UFLA-FAEPE, 1997. p.127-163.

BERGEN, W.G.; BATES, D.B. Ionophores: their effect on production efficiency and mode of action. J. Anim. Sci., v.58, p.1465-83, 1984.

BERGMAN, E.N. Energy contributions of volatile fatty acids from the gastrointestinal tract in various species. Physiol. Rev., v.70, p.567590, 1990. 
GEHMAN, A.M.; KONONOFF, P.J.; MULLINS, C.R. et al. Evaluation of nitrogen utilization and the effects of monensina in dairy cows fed brown midrib corn silage. J. Dairy Sci., v.91, p.288-230, 2008.

JACQUES, K.A.; COCHRAN, R.C.; CORAH, L.R. Influence of lasalocid level on forage intake, digestibility, ruminal fermentation, liquid flow and performance of beef cattle grazing winter range. J. Anim. Sci., v.65, p.777-85, 1987.

KNOWLTON, K.F.; ALLEN, M.S.; ERICKSON, P.S. Lasolocid and particle size of corn grain for dairy cows in early lactation.1. Effect on performance, serum metabolites and nutrient digestibility. J. Dairy Sci., v.79, p.557564, 1996.

LENG, R.A. Supplementation of tropical and subtropical pastures for ruminants production. In: GILCHRIST, F.M.C.; MAcKIE, R.L. (Eds). Herbivore nutrition in the subtropics and tropics. Pretoria: The Science Press, 1984. p.129-144.

MARTINEAU, R.; BENCHAAR, C.; PETIT, H.V. et al. Effects of lasalocid or monensin supplementation on digestion, ruminal fermentation, blood metabolites, and milk production of lactating dairy cows. J. Dairy Sci., v.90, p.5714-5725, 2007.

MERTENS, D.R. Análise da fibra e sua utilização na avaliação de alimentos e formulação de rações. In: REUNIÃO ANUAL DA SOCIEDADE BRASILEIRA DE ZOOTECNIA, 29., 1992, Lavras. Anais... Lavras: SBZ, 1992. p.188-219.

McGUFFEY, R.K.; RICHARDISON, L.F.; WILKINSON, J.I.D. Ionophores of dairy cattle: current status and future outlook. J. Dairy Sci., v.84, suppl., p.E194-E203, 2001.

MINSON, D.J. Forage in ruminant nutrition. London: Academic, 1990. 483p.

OFFICIAL methods of analysis. 15.ed. Arlington, VA: AOAC, 1990. 1141p.

OLIVEIRA, M.V.M.; LANA, R.P.; JHAM, G.N. et al. Influência da monensina no consumo e na fermentação ruminal em bovinos recebendo dietas com teores baixo e alto de proteína. Rev. Bras. Zootec., v.34, p.1763-1774, 2005.
ORSKOV, E.R.; McDONALD, I. The estimation of protein degradability in the rumen from incubation measurements weighted according to rate of passage. J. Agric. Sci., v.92, p.499-503, 1979.

PAULINO, M.F.; ZERVOUDAKIS, J.T; MORAES, E.H.B.K. et al. Suplementação múltipla para bovinocultura de ciclo curto em pastagens. In: SIMPÓSIO DE PECUÁRIA DE CORTE, 2., 2002, Lavras. Anais... Lavras: UFLA, 2002. p.199-254.

RIBEIRO, M.D.; PEREIRA, J.C.; VIEIRA, R.A.M. et al. Consumo e desempenho de novilhas em pastagem recebendo suplementos com diferentes níveis de proteína não degradável no rúmen. Rev. Bras. Zootec., v.34, p.2486-2495, 2005.

RODRIGUES, P.H.M.; LUCCI, C.S.; MELOTTI, L. Efeitos da lasalocida sódica e proporção volumoso/concentrados sobre a degradabilidade in situ do farelo de soja e do feno coast cross [Cynodon dactylon (L.) Pers.] em vacas secas. Braz. J. Vet. Res. Anim. Sci., v.37, p.259-264, 2000.

RUAS, J.R.M.; TORRES, C.A.A.; VALADARES FILHO, S.C. Efeito da suplementação proteica a pasto sobre consumo de forragens, ganho de peso e condição corporal em vacas Nelore. Rev. Bras. Zootec., v.29, p.930-934, 2000.

SATTER, L.D.; SLYTER, L.L. Effect of ammonia concentration in rumem microbial protein production in vitro. Br. J. Nutr., v.32, p.199-205, 1974.

SILVA, D.J.; QUEIROZ, A.C. Análise de alimentos: métodos químicos e biológicos. 3.ed. Viçosa: UFV, 2002. 235p.

VAN SOEST, P.J. Nutrition ecology of the ruminant. 2.ed. Ithaca, NY: Cornell University, 1994. 476p.

VAN SOEST, P.J.; ROBERTSON, J.B.; LEWIS, B.A. Methods for dietary fiber, neutral detergent fiber, nonstarch polysacsharides in relation to animal nutrition. J. Dairy Sci., v.74, p.35833597, 1991. 